\title{
DOSES DE NITROGÊNIO E MODOS DE APLICAÇÃO DE POLÍMEROS ORGÂNICOS COM UREIA DISSOLVIDA NA CULTURA DO MILHO
}

Fernando Henrique Queiroz Souza ${ }^{1 *}$, Marcelo Carvalho Minhoto Teixeira Filho ${ }^{2}$, Fernando Shintate Galindo ${ }^{3}$, Luiz Francisco Malmonge ${ }^{4}$, José Antonio Malmonge ${ }^{5}$, Salatier Buzetti ${ }^{6}$

\footnotetext{
${ }^{1}$ Engenheiro Agrônomo - Universidade Estadual Paulista (UNESP), Faculdade de Engenharia, Ilha Solteira SP. *Email: fernandoqsouza@yahoo.com.br

${ }^{2}$ Professor do Departamento de Fitossanidade, Engenharia Rural e Solos - Universidade Estadual Paulista (UNESP), Faculdade de Engenharia, Ilha Solteira - SP.

${ }^{3}$ Doutorando em Agronomia, Sistemas de Produção - Universidade Estadual Paulista (UNESP), Faculdade de Engenharia, Ilha Solteira - SP.

${ }^{4}$ Professor do Departamento de Física e Química - Universidade Estadual Paulista (UNESP), Faculdade de Engenharia, Ilha Solteira - SP.

${ }^{5}$ Professor do Departamento de Física e Química - Universidade Estadual Paulista (UNESP), Faculdade de Engenharia, Ilha Solteira - SP.

${ }^{6}$ Professor do Departamento de Fitossanidade, Engenharia Rural e Solos - Universidade Estadual Paulista (UNESP), Faculdade de Engenharia, Ilha Solteira - SP.
}

RESUMO: A eficiência da adubação nitrogenada com ureia pode e deve ser melhorada, por isso, são importantes pesquisas com formas alternativas de ureia em função da disponibilização gradual do nitrogênio. Sendo assim, objetivou-se avaliar doses e modos de aplicação de ureia ou de polímeros orgânicos com ureia dissolvida e incorporada, no estado nutricional e desenvolvimento da planta de milho. $\mathrm{O}$ experimento foi realizado em casa de vegetação durante 60 dias, em Ilha Solteira - SP. O delineamento experimental utilizado foi em blocos ao acaso com quatro repetições, dispostos em um esquema fatorial $3 \times 2 \times 2$, sendo: 3 fontes de $\mathrm{N}(\mathrm{C} 1$ = polímero orgânico com $30 \%$ de ureia dissolvida e 6,86\% de $\mathrm{N}, \mathrm{C} 2=$ polímero orgânico com e $70 \%$ de ureia dissolvida e $19,35 \%$ de N, ou ureia convencional), 2 doses de $\mathrm{N}$ ( 50 ou $100 \mathrm{mg} \mathrm{dm}^{-3}$ ) e 2 modos de aplicação (incorporado ou em superfície). De maneira geral, a altura de planta e o diâmetro do colmo do milho não foram influenciados pelos modos de aplicação, fontes e doses de $\mathrm{N}$. A dose de $100 \mathrm{mg} \mathrm{dm}^{-3}$ de $\mathrm{N}$ proporcionou maior teor de $\mathrm{N}$ na planta, quando utilizado o polímero $\mathrm{C} 1$ e a ureia. $\mathrm{O}$ modo de aplicação não interferiu nos teores de $\mathrm{N}, \mathrm{P}$ e $\mathrm{K}$ na planta. O polímero orgânico $\mathrm{C} 1$ mostrou-se mais promissor no fornecimento de $\mathrm{N}$ à planta de milho, devido ao incremento de matéria seca de planta na dose de $50 \mathrm{mg} \mathrm{dm}^{-3}$ de $\mathrm{N}$ comparativamente à ureia e o polímero $\mathrm{C} 2$.

Palavras-chave: Zea mays. Fertilizantes de liberação gradual. Adubação nitrogenada.

\section{NITROGEN RATES AND ORGANIC POLYMERS APPLICATION MODES WITH DISSOLVED UREA IN MAIZE}

\begin{abstract}
The efficiency of nitrogen fertilizer urea can and should be improved, therefore, are important research into alternative forms of urea due to the gradual release of
\end{abstract}

Cultura Agronômica, Ilha Solteira, v.25, n.4, p.361-372, 2016 
nitrogen. Therefore, aimed to evaluate doses and urea application modes or organic polymers with urea dissolved and incorporated, nutritional status and development of maize plant. The experiment was conducted in a greenhouse for 60 days in Ilha Solteira - SP. The experimental design was a randomized block with four replications, in a factorial $3 \times 2 \times 2$, where 3 sources of $\mathrm{N}(\mathrm{C} 1=$ organic polymer with $30 \%$ dissolved urea and $6.86 \% \mathrm{~N}, \mathrm{C} 2=$ organic polymer dissolved and $70 \%$ of urea and $19.35 \%$ of $\mathrm{N}$, or conventional urea), $\mathrm{N} 2$ rates (50 or $100 \mathrm{mg}$ $\mathrm{dm}^{-3}$ ) and two application methods (incorporated or in surface). In general, the plant height and the stalk diameter of maize were not influenced by application modes, sources and rates of $\mathrm{N}$. The rates of $100 \mathrm{mg} \mathrm{dm}^{-3} \mathrm{~N}$ gave higher $\mathrm{N}$ content in plant when used $\mathrm{C} 1$ polymer and urea. The mode of application did not affect the concentrations of $\mathrm{N}, \mathrm{P}$ and $\mathrm{K}$ in the plant. The organic polymer $\mathrm{C} 1$ was more promising in providing $\mathrm{N}$ to the maize plant due to the increase of plant dry matter at the rate of $50 \mathrm{mg} \mathrm{dm}^{-3}$ of $\mathrm{N}$ compared to urea polymer and $\mathrm{C} 2$.

Key words: Zea mays. Gradual release fertilizer. Nitrogen fertilization.

\section{INTRODUÇÃO}

O milho é uma das culturas mais antigas e difundidas no mundo. Apesar dos avanços tecnológicos disponíveis, a produtividade média brasileira ainda é muito baixa, em torno de $5.401 \mathrm{~kg} \mathrm{ha}^{-1}$, levando-se em consideração safra e safrinha. Isso demonstra a necessidade de buscar técnicas de manejo para obter incremento de produtividade e por consequência garantir lucros ao produtor (CONAB, 2015).

Como forma de suprir a necessidade de consumo de alimentos no mundo, tem-se intensificado as áreas de cultivo visando maiores produtividades, principalmente por meio de fortes investimentos em pesquisa e desenvolvimento agrícola, principalmente na obtenção de variedades melhoradas e no aumento da eficiência no uso de insumos agrícolas pelas plantas. Dentre os insumos utilizados na agricultura, os fertilizantes nitrogenados são os que mais oneram o custo de produção, em função do potencial elevado de perdas por volatilização, lixiviação e nitrificação, haja vista que nenhum outro elemento apresenta dinamismo tão grande como o nitrogênio (N) (ROBERTSON; GROFFMAN, 2007).

O N pode ser aplicado ao solo por diferentes métodos, sendo o mais comum a lanço, na superfície do solo e incorporado em linhas. Quando a fonte de $\mathrm{N}$ for a ureia, a mais comumente utilizada na agricultura, e não ocorrer chuva nos primeiros dias após a aplicação, a incorporação ao solo pode ser importante, para minimizar a formação de amônia $\left(\mathrm{N}-\mathrm{NH}_{3}\right)$ e sua liberação para a atmosfera. Em estudos conduzidos por Cabezas et al. (2000), estima-se que pode haver redução na produtividade de grãos de milho devido à volatilização de $\mathrm{N}-\mathrm{NH}_{3}$, na proporção de $10 \mathrm{~kg} \mathrm{ha}^{-1}$ de grãos para cada $1 \%$ de $\mathrm{N}$ volatilizado. Desta forma, diversos produtos à base de ureia são desenvolvidos buscando maior eficiência em seu uso, o que promove avanços tecnológicos na área de insumos.

Cultura Agronômica, Ilha Solteira, v.25, n.4, p.361-372, 2016 
Dentre esses avanços, há uma vertente de pesquisa em foco que abrange os fertilizantes recobertos, ou seja, grânulos da ureia revestidos com diversos materiais (resinas, ceras, polímeros, etc.) (CIVARDI et al., 2011). As perdas por volatilização ocorrem em consequência da atuação nos mecanismos de contato do fertilizante com a enzima urease presente no solo. Com o revestimento, busca-se diminuir essa perda, já que o fertilizante estará protegido dentro de sua capsula de recobrimento. O recobrimento deste fertilizante com polímeros, busca a otimização das fontes disponíveis no mercado e pode, dependendo da característica dos polímeros, aumentar a eficiência de uso pelo mecanismo de liberação gradual do nutriente (RODRIGUES et al., 2014).

O uso de fertilizante nitrogenado de liberação controlada pode fornecer vários benefícios, como aumento na produtividade, economia de trabalho, já que pode diminuir o número de parcelamentos e impacto ambiental devido à menor lixiviação do nitrato, desde que combinado com a demanda da cultura e as condições de desenvolvimento (CIVARDI et al., 2011). Segundo Valderrama et al. (2011), a ureia revestida por polímeros e a convencional tem a mesma eficiência na nutrição e na produtividade de grãos de milho. Ainda segundo estes autores, o revestimento não tem sido eficaz nas condições edafoclimáticas de Cerrado de baixa altitude, por se tratar de condições onde predominam altas temperaturas. Sendo assim, ainda há necessidade de novas pesquisas para o desenvolvimento de polímeros para o revestimento ou fornecimento da ureia, que possam resistir às altas temperaturas que são comuns nesta região.

Diante do exposto, objetivou-se com este trabalho avaliar o efeito de doses e do modo de aplicação de ureia ou de polímeros orgânicos com ureia dissolvida e incorporada, no estado nutricional e desenvolvimento da planta de milho.

\section{MATERIAL E MÉTODOS}

O experimento foi conduzido em casa de vegetação na Universidade Estadual Paulista (FEIS/UNESP), Câmpus de Ilha Solteira. As coordenadas geográficas são de $20^{\circ} 25^{\prime}$ latitude Sul e $51^{\circ} 20^{\prime}$ longitude Oeste, com altitude de aproximadamente 335 metros. O solo utilizado foi classificado como um Latossolo Vermelho álico, de textura argilosa (EMBRAPA, 2013).

As características químicas do solo determinadas antes da instalação do experimento em 2012, segundo metodologia proposta por Raij et al. (2001) apresentaram os seguintes resultados: $\mathrm{P}$ resina $=1 \mathrm{mg} \mathrm{dm}^{-3}, \mathrm{pH} \mathrm{CaCl}_{2}=4,1 ; \mathrm{K}, \mathrm{Ca}, \mathrm{Mg}, \mathrm{H}+\mathrm{Al}=0,5,1,0,1,0$ e 34,0 $\mathrm{mmol}_{\mathrm{c}} \mathrm{dm}^{-3}$, respectivamente. Os teores de $\mathrm{S}_{-} \mathrm{SO}_{4}, \mathrm{~B}, \mathrm{Cu}, \mathrm{Fe}, \mathrm{Mn}$ e $\mathrm{Zn}$ (DTPA) foram de 4,0, $0,22,1,0,34,0,5,3$ e $0,4 \mathrm{mg} \mathrm{dm}^{-3}$, respectivamente; com saturação de bases de $7 \%$ e saturação de alumínio de $83 \%$.

O delineamento experimental utilizado foi em blocos ao acaso com quatro repetições, dispostos em um esquema fatorial $3 \times 2 \times 2$, sendo: 3 fontes de $\mathrm{N}(\mathrm{C} 1=$ polímero orgânico com 30\% de ureia dissolvida e incorporada e 6,86\% de N, C2 = polímero orgânico com e 70\% ureia dissolvida e incorporada e 19,35\% de N, C3 = ureia convencional com 45\% de N), 2 
doses de $\mathrm{N}$ (50 ou $100 \mathrm{mg} \mathrm{dm}^{-3}$ ) e 2 modos de aplicação (incorporado à $3 \mathrm{~cm}$ de profundidade ou em superfície).

Antes da instalação do experimento, realizou-se a calagem na dose de 2,56 t ha ${ }^{-1}$ (equivalente a 5,12 g de calcário por vaso com quatro litros de solo), em todo o solo utilizado para encher os vasos, dois meses antes da semeadura do milho, seguindo recomendação de Cantarella et al. (1997).

Após preparação das amostras com a ureia dissolvida e incorporada no polímero orgânico a base de látex no Departamento de Física e Química da UNESP - Câmpus de Ilha Solteira, estas foram cortadas e padronizadas com cerca de $2 \mathrm{~mm}$ de espessura e $0,50 \mathrm{~cm}^{2}$. Os vasos utilizados continham $4 \mathrm{dm}^{3}$ de solo e a semeadura do hibrido de milho AG8088 e aplicação dos tratamentos foram realizadas no dia 02 de agosto de 2012, sendo semeadas três sementes em cada vaso. Após a emergência das plantas foi efetuado o desbaste, deixando apenas uma planta por vaso. Os vasos foram distribuídos de forma aleatória em cada bloco na casa de vegetação, sendo espaçados de $0,90 \mathrm{~m}$ nas entre linhas e 0,20 m entre vasos com plantas na linha.

A adubação foi efetuada com base na análise de solo e seguindo a recomendação para experimentos em vaso (MALAVOLTA, 1980), onde na adubação de semeadura foram aplicados $200 \mathrm{mg} \mathrm{dm}^{-3}$ de P (Superfosfato simples, o qual forneceu $50 \mathrm{mg} \mathrm{dm}^{-3} \mathrm{de} \mathrm{S}$ ), $50 \mathrm{mg}$ $\mathrm{dm}^{-3}$ de $\mathrm{K}$ (Cloreto de potássio), 0,5 $\mathrm{mg} \mathrm{dm}^{-3}$ de B (Ácido bórico) e $5 \mathrm{mg} \mathrm{dm}^{-3}$ de Zn (Sulfato de zinco). Os tratamentos (doses e fontes de $\mathrm{N}$ ) foram todos aplicados na semeadura do milho, com as fontes sendo aplicadas equidistantes em relação à semente. A adubação de cobertura foi realizada aos 43 dias após a emergência das plântulas, aplicando-se $50 \mathrm{mg} \mathrm{dm}^{-3} \mathrm{de} \mathrm{K}$ (Cloreto de potássio).

A irrigação foi realizada igualmente para todos os tratamentos conforme a necessidade da cultura. Foram realizadas as seguintes avaliações: a) altura de planta $(\mathrm{H})$, utilizando-se uma régua graduada em centímetros, medindo-se a distância do colo ao ápice da planta (final do cartucho); b) diâmetro do colmo (D), avaliando-se o segundo internódio com auxílio de um paquímetro; c) índice de clorofila foliar (ICF), utilizando-se um clorofilômetro portátil foram realizadas três leituras de ICF no terço médio da última folha recém expandida da planta, e foi calculado a média entre elas. As leituras foram realizadas em pontos situados entre a metade à dois terços do comprimento da folha amostrada, a partir da base, e a $2 \mathrm{~cm}$ de uma das margens da folha. As avaliações, tanto de altura $(\mathrm{H})$, diâmetro do colmo (D) e índice de clorofila (ICF) foram realizadas nos dias 24/08/12 (H1, D1 e ICF1), 12/09/12 (H2, D2 e ICF 2) e 29/09/12 (D3 e ICF 3), respectivamente.

Após 60 dias da emergência das plântulas, foi realizada a colheita da planta de milho, com o corte efetuado rente ao solo, e posteriormente, o material foi acondicionado para secagem em estufa de circulação de ar forçada, com temperatura média de $65^{\circ} \mathrm{C}$, por cerca de 72 horas. Em seguida, as amostras foram pesadas para determinação da produtividade da massa seca (g por planta). Posteriormente, foi realizada a moagem do material em moinho

Cultura Agronômica, Ilha Solteira, v.25, n.4, p.361-372, 2016 
tipo Wiley, equipado com peneira com crivos de $2 \mathrm{~mm}$, e foram realizadas as análises químicas de parte aérea para determinação dos teores de N, P e K, seguindo metodologia de Malavolta et al., (1997).

Os parâmetros avaliados foram submetidos à análise de variância (teste F) e as médias das fontes e doses de $\mathrm{N}$ e do modo de aplicação, bem como o desdobramento das interações foram comparadas pelo teste de Tukey a 5\% de probabilidade. Para análise estatística foi utilizado o programa SISVAR (FERREIRA, 2011).

\section{RESULTADOS E DISCUSSÃO}

Com relação às fontes de $\mathrm{N}$ (Tabela 1), o ICF2 e ICF3, assim como os teores de $\mathrm{P}$ e K na planta de milho não foram influenciados pelos polímeros orgânicos $\mathrm{C} 1$ e C2 e a ureia convencional. Entretanto, a ureia proporcionou maior ICF1 comparativamente ao polímero $\mathrm{C} 2$, não diferindo do polímero $\mathrm{C} 1$. Como esta foi a primeira avaliação realizada, provavelmente houve liberação inicial de $\mathrm{N}$ mais lenta no polímero $\mathrm{C} 2$, o que refletiu em menor ICF, já que este nutriente está presente na molécula de clorofila, justificando tal redução da clorofila foliar.

As doses de $\mathrm{N}$ não influenciaram os teores de $\mathrm{P}$ e K na planta de milho e ICF1 e ICF2. Porém, a maior dose de $\mathrm{N}\left(100 \mathrm{mg} \mathrm{dm}^{-3}\right)$ proporcionou maior ICF3 comparativamente à dose de $50 \mathrm{mg} \mathrm{dm}^{-3}$ de $\mathrm{N}$ (Tabela 1), corroborando com os resultados obtidos por outros pesquisadores (COSTA et al., 2012; KAPPES et al., 2013). Ressalta-se ainda que a falta de relação entre a leitura do clorofilômetro e o teor de $\mathrm{N}$ na cultura do milho, nos estádios iniciais, de seis a sete folhas, indicam que boa parte do $\mathrm{N}$ absorvido nessa fase é provavelmente utilizado para produção de outras estruturas na planta e não para formação de clorofila. Além disso, a demanda total da planta em nitrogênio é pequena na fase inicial de desenvolvimento, enquanto que no período usual de aplicação de $\mathrm{N}$ em cobertura (4 a 8 folhas), a absorção deste nutriente pelas plantas é mais intensa, o que justificaria a diferença no ICF na avaliação efetuada mais tardiamente, próxima do pico de exigência nutricional da cultura.

O modo de aplicação das fontes de N não interferiu nos teores de N, P e K na planta, bem como no ICF1 e ICF2, entretanto, o ICF3 foi superior com a incorporação das fontes de $\mathrm{N}$, comparativamente à aplicação em superfície (Tabela 1). Embora não tenha sido verificado diferença no teor de $\mathrm{N}$ na planta, o valor médio obtido foi um pouco maior quando as fontes de $\mathrm{N}$ foram incorporadas ao solo, equivalente a 7,7\% superior comparativamente à aplicação em superfície, indicando que pode ter ocorrido volatilização da amônia, mesmo com irrigação, demonstrando que a incorporação da ureia pode ser vantajosa em relação às perdas de $\mathrm{N}$ por volatilização, minimizando a formação de amônia $\left(\mathrm{N}-\mathrm{NH}_{3}\right)$ e sua liberação para a atmosfera.

Segundo Silva et al. (2005), a incorporação do fertilizante nitrogenado na semeadura ou aos 15 dias após a emergência das plântulas, pode aumentar a produtividade em até 670 $\mathrm{kg} \mathrm{ha}^{-1}$ em relação à aplicação em superfície. Pöttker e Wiethölter (2004) também verificaram, 
na média de cinco anos de avaliação, que a incorporação do $\mathrm{N}$ ao solo aumentou a produtividade de grãos de milho em cerca de $5 \%$, em relação à sua aplicação em cobertura sem incorporação, para as condições do Rio Grande do Sul.

Tabela 1. Teores foliares de N, P e K e índices de clorofila foliar (ICF) de plantas de milho em função de fontes, doses e modos de aplicação de nitrogênio. Ilha Solteira - SP, 2012.

\begin{tabular}{ccccccc}
\hline & $\mathrm{N}$ & $\mathrm{P}$ & $\mathrm{K}$ & $\mathrm{ICF}$ ** $^{*}$ & $\mathrm{ICF} 2 * *$ & ICF3** \\
& & & & & & \\
\hline Fontes de N & & & & & & \\
C1 ${ }^{*}$ & 10,64 & $1,49 \mathrm{a}$ & $16,16 \mathrm{a}$ & $27,56 \mathrm{ab}$ & $41,31 \mathrm{a}$ & $28,00 \mathrm{a}$ \\
$\mathrm{C} 2$ & 9,29 & $1,51 \mathrm{a}$ & $17,56 \mathrm{a}$ & $26,01 \mathrm{~b}$ & $38,56 \mathrm{a}$ & $25,78 \mathrm{a}$ \\
Ureia & 9,71 & $1,48 \mathrm{a}$ & $16,06 \mathrm{a}$ & $30,10 \mathrm{a}$ & $39,34 \mathrm{a}$ & $25,86 \mathrm{a}$ \\
\hline D.M.S. (5\%) & 1,74 & 0,25 & 2,37 & 2,88 & 3,66 & 2,42 \\
\hline Doses de N (mg dm $\left.{ }^{-3}\right)$ & & & & & & \\
50 & 9,08 & $1,47 \mathrm{a}$ & $16,50 \mathrm{a}$ & $28,71 \mathrm{a}$ & $38,76 \mathrm{a}$ & $24,74 \mathrm{~b}$ \\
100 & 10,68 & $1,51 \mathrm{a}$ & $16,69 \mathrm{a}$ & $27,07 \mathrm{a}$ & $40,71 \mathrm{a}$ & $28,35 \mathrm{a}$ \\
\hline D.M.S. (5\%) & 1,18 & 0,17 & 1,60 & 1,95 & 2,48 & 1,64 \\
\hline Modo de aplicação & & & & & & \\
Incorporado & $10,28 \mathrm{a}$ & $1,54 \mathrm{a}$ & $16,29 \mathrm{a}$ & $27,55 \mathrm{a}$ & $40,57 \mathrm{a}$ & $28,13 \mathrm{a}$ \\
Em superfície & $9,49 \mathrm{a}$ & $1,45 \mathrm{a}$ & $16,90 \mathrm{a}$ & $28,23 \mathrm{a}$ & $38,90 \mathrm{a}$ & $24,96 \mathrm{~b}$ \\
\hline D.M.S. (5\%) & 1,18 & 0,17 & 1,60 & 1,95 & 2,48 & 1,64 \\
\hline Média geral & 9,88 & 0,17 & 16,59 & 27,89 & 39,74 & 26,54 \\
\hline C.V. (\%) & 20,30 & 19,46 & 16,44 & 11,91 & 10,61 & 10,51 \\
\hline
\end{tabular}

Médias seguidas de letra iguais, na coluna, não diferem entre si pelo teste de Tukey a 5\% de probabilidade. ${ }^{*} \mathrm{C} 1$ = Polímero orgânico com $30 \%$ de ureia, perfazendo 6,86\% de N; $22=$ Polímero orgânico com $70 \%$ de ureia, perfazendo $19,35 \%$ de $\mathrm{N}$; Ureia $=45 \%$ de $\mathrm{N}$.

**ICF1, ICF2 e ICF3 = são respectivamente a primeira, segunda e terceira avaliação do índice de clorofila foliar.

A interação entre fontes e doses de $\mathrm{N}$ foi significativa para o teor de $\mathrm{N}$ em parte aérea (Tabela 2), onde as fontes $\mathrm{C} 1$ e ureia propiciaram maior teor de $\mathrm{N}$ na dose de $100 \mathrm{mg} \mathrm{dm}^{-3}$ comparativamente à dose de $50 \mathrm{mg} \mathrm{dm}^{-3}$. $\mathrm{O}$ aumento no teor de $\mathrm{N}$ foliar em função das doses aplicadas do nutriente demonstra a importância da nutrição com $\mathrm{N}$ na absorção de nutrientes, a qual pode ser explicada pelo maior crescimento da parte aérea e raízes, com reflexo na absorção de água e nutrientes. Resultados semelhantes foram obtidos por Mar et al. (2003), Soratto et al. (2010), Souza et al. (2011) e Costa et al. (2012), que verificaram efeito positivo das doses de $\mathrm{N}$ na concentração de $\mathrm{N}$ foliar, até as doses de 150,120, 170 e $200 \mathrm{~kg} \mathrm{ha}^{-1}$ de N, respectivamente.

$\mathrm{Na}$ dose de $50 \mathrm{mg} \mathrm{dm}^{-3}$ de $\mathrm{N}$ (Tabela 2), as fontes propiciaram teor de $\mathrm{N}$ semelhante, entretanto, verificou-se que na dose de $100 \mathrm{mg} \mathrm{dm}^{-3}$ de $\mathrm{N}$ houve maior teor de $\mathrm{N}$ na planta, quando se utilizou o polímero orgânico $\mathrm{C} 1$ e a ureia, não diferindo do polímero $\mathrm{C} 2$. Estes resultados indicam que o polímero orgânico $\mathrm{C} 1$ com $30 \%$ de ureia dissolvida e incorporada é mais promissor que o polímero $\mathrm{C} 2 \mathrm{com} 70 \%$, já que o mesmo em menor concentração apresentou maior teor de $\mathrm{N}$ na planta. 
Tabela 2. Desdobramento da interação fonte e dose de nitrogênio, da análise de variância referente ao teor de $\mathrm{N}\left(\mathrm{g} \mathrm{kg}^{-1}\right)$ de plantas milho. Ilha Solteira, 2012.

\begin{tabular}{cccc}
\hline Tratamentos & \multicolumn{3}{c}{ Fontes de N } \\
\hline Doses de $\mathrm{N}\left(\mathrm{mg} \mathrm{dm}^{-3}\right)$ & $\mathrm{C} 1^{*}$ & $\mathrm{C} 2 *$ & Ureia \\
\hline 50 & $9,34 \mathrm{bA}$ & $9,25 \mathrm{aA}$ & $8,65 \mathrm{bA}$ \\
100 & $11,94 \mathrm{aA}$ & $9,34 \mathrm{aB}$ & $10,78 \mathrm{aAB}$ \\
\hline \multirow{2}{*}{ D.M.S. (5\%) } & Fontes de N & 2,04 & \\
& Doses de N & 2,46 & \\
\hline
\end{tabular}

Médias seguidas de mesma letra, minúsculas nas colunas e maiúsculas nas linhas, não diferem estatisticamente entre si pelo teste de Tukey a $5 \%$ de probabilidade.

${ }^{*} \mathrm{C} 1$ = Polímero orgânico com $30 \%$ de ureia, perfazendo 6,86\% de N; C2 = Polímero orgânico com 70\% de ureia, perfazendo $19,35 \%$ de $\mathrm{N}$; Ureia $=45 \%$ de $\mathrm{N}$.

A altura de planta e o diâmetro do colmo do milho não foram influenciados pelos modos de aplicação e pelas doses de N (Tabela 3), corroborando com Valderrama et al. (2011), trabalhando com ureia e ureia revestida nas doses de $0,50,100$ e $150 \mathrm{~kg} \mathrm{ha}^{-1}$ de $\mathrm{N}$ em cobertura, constataram que tais avaliações não foram influenciadas. Resultados semelhantes também foram obtidos por Costa et al. (2012), trabalhando com as doses de 0, 50, 100, $150 \mathrm{e}$ $200 \mathrm{~kg} \mathrm{ha}^{-1}$ de $\mathrm{N}$ em cobertura não verificaram influência no diâmetro do colmo, entretanto, segundo os autores as doses de $\mathrm{N}$ influenciaram a altura de planta. Cruz et al. (2008), verificaram que doses acima de $80 \mathrm{~kg} \mathrm{ha}^{-1}$ de $\mathrm{N}$, não contribuíram para o aumento do diâmetro do colmo e altura de planta de milho.

Tabela 3. Alturas de planta (H), diâmetros do colmo (D) e matéria seca de planta de milho em função de fontes, doses e modos de aplicação de nitrogênio. Ilha Solteira - SP, 2012.

\begin{tabular}{|c|c|c|c|c|c|c|}
\hline & H1 & $\mathrm{H} 2$ & D1 & D2 & D3 & Matéria seca \\
\hline & $----\cdot$ & & $--(\mathrm{cm})---$ & ------ & ------- & (g por planta) \\
\hline \multicolumn{7}{|l|}{ Fontes de $\mathrm{N}$} \\
\hline $\mathrm{C} 1 *$ & 122,48 a & $145,25 \mathrm{a}$ & $1,05 \mathrm{ab}$ & $1,19 \mathrm{a}$ & $1,16 \mathrm{a}$ & 42,55 \\
\hline $\mathrm{C} 2$ & $115,69 \mathrm{a}$ & $138,94 \mathrm{a}$ & $0,94 \mathrm{~b}$ & $1,12 \mathrm{a}$ & $1,16 \mathrm{a}$ & 39,08 \\
\hline Ureia & $117,00 \mathrm{a}$ & $143,63 \mathrm{a}$ & $1,09 \mathrm{a}$ & $1,17 \mathrm{a}$ & $1,18 \mathrm{a}$ & 40,76 \\
\hline D.M.S. (5\%) & 10,68 & 11,20 & 0,13 & 0,09 & 0,12 & 3,47 \\
\hline \multicolumn{7}{|c|}{ Doses de $\mathrm{N}\left(\mathrm{mg} \mathrm{dm}^{-3}\right)$} \\
\hline 50 & $118,21 \mathrm{a}$ & $144,29 \mathrm{a}$ & $1,06 \mathrm{a}$ & $1,16 \mathrm{a}$ & $1,16 \mathrm{a}$ & 39,14 \\
\hline 100 & $118,57 \mathrm{a}$ & $140,92 \mathrm{a}$ & $0,99 \mathrm{a}$ & $1,16 \mathrm{a}$ & $1,17 \mathrm{a}$ & 42,45 \\
\hline D.M.S. $(5 \%)$ & 7,23 & 7,58 & 0,09 & 0,06 & 0,08 & 2,35 \\
\hline \multicolumn{7}{|l|}{ Modo de aplicação } \\
\hline Incorporado & $115,71 \mathrm{a}$ & $143,25 \mathrm{a}$ & $1,00 \mathrm{a}$ & $1,16 \mathrm{a}$ & $1,17 \mathrm{a}$ & 41,13 \\
\hline Em superfície & $121,07 \mathrm{a}$ & $141,96 \mathrm{a}$ & $1,05 \mathrm{a}$ & $1,16 \mathrm{a}$ & $1,16 \mathrm{a}$ & 40,47 \\
\hline D.M.S. (5\%) & 7,23 & 7,58 & 0,09 & 0,06 & 0,08 & 2,35 \\
\hline Média geral & 118,39 & 142,60 & 1,03 & 1,16 & 1,16 & 40,80 \\
\hline C.V. (\%) & 10,40 & 9,05 & 14,59 & 8,95 & 11,81 & 9,80 \\
\hline
\end{tabular}

Cultura Agronômica, Ilha Solteira, v.25, n.4, p.361-372, 2016 
Com relação às fontes de $\mathrm{N}$ (Tabela 3), os polímeros orgânicos $\mathrm{C} 1$ e $\mathrm{C} 2$ e a ureia convencional não diferiram para as alturas de planta (H1 e H2), assim como para os diâmetros de colmo (D2 e D3) de milho. Porém, ressalta-se tendência de maior altura de planta quando se utilizou o polímero $\mathrm{C} 1$, que pode ser em função do polímero $\mathrm{C} 1$ ter propiciado maior teor de $\mathrm{N}$ na planta quando comparado à ureia convencional e o polímero $\mathrm{C} 2$. A ureia proporcionou maior D1, diferindo apenas do polímero C2 (Tabela 3). Como esta foi a primeira avaliação realizada, provavelmente houve liberação inicial de $\mathrm{N}$ mais lenta no polímero $\mathrm{C} 2$, o que refletiu em menor diâmetro de colmo.

A interação entre fontes e doses de $\mathrm{N}$ foi significativa (Tabela 4), onde na dose $50 \mathrm{mg}$ $\mathrm{dm}^{-3}$ de $\mathrm{N}$, o polímero orgânico $\mathrm{C} 1$ proporcionou maior matéria seca de planta de milho, em relação ao polímero $\mathrm{C} 2$ e a ureia. $\mathrm{Na}$ dose de $100 \mathrm{mg} \mathrm{dm}^{-3}$ de $\mathrm{N}$ não houve diferença significativa entre as fontes de $\mathrm{N}$ para tal avaliação. Tanto o polímero C2 quanto a ureia propiciaram maior incremento de matéria seca na maior dose de $\mathrm{N}\left(100 \mathrm{mg} \mathrm{dm}^{-3}\right)$. Entretanto, para o polímero $\mathrm{C} 1$ não houve diferença entre as doses de $\mathrm{N}$, sendo que em ambas as doses foram obtidos bons valores de matéria seca de planta para este polímero orgânico a base de látex com ureia dissolvida.

Tabela 4. Desdobramento da interação fonte de $\mathrm{N}$ e dose de nitrogênio, da análise de variância referente à matéria seca de planta de milho (g por planta). Ilha Solteira - SP, 2012.

\begin{tabular}{cccc}
\hline Tratamentos & \multicolumn{4}{c}{ Fontes de N } \\
\hline Doses de N $\left(\mathrm{mg} \mathrm{dm}^{-3}\right)$ & $\mathrm{C} 1^{*}$ & $\mathrm{C} 2$ & Ureia \\
\hline 50 & $42,73 \mathrm{aA}$ & $37,26 \mathrm{aB}$ & $37,44 \mathrm{bB}$ \\
100 & $42,38 \mathrm{aA}$ & $40,91 \mathrm{aA}$ & $44,08 \mathrm{aA}$ \\
\hline \multirow{2}{*}{ D.M.S. (5\%) } & Fontes de N & & 4,07 \\
& Doses de N & 4,91 & \\
\hline
\end{tabular}

Médias seguidas de mesma letra, minúsculas nas colunas e maiúsculas nas linhas, não diferem estatisticamente entre si pelo teste de Tukey a $5 \%$ de probabilidade.

${ }^{*} \mathrm{C} 1$ = Polímero orgânico com $30 \%$ de ureia, perfazendo 6,86\% de N; C2 = Polímero orgânico com 70\% de ureia, perfazendo $19,35 \%$ de N; Ureia $=45 \%$ de $\mathrm{N}$.

Valderrama et al. (2011), não constataram diferença entre a ureia convencional e revestida por polímeros para produtividade de grãos de milho na safra de verão na região de cerrado. Em contrapartida, Pereira et al. (2009) verificaram em Jataí - GO, região de Cerrado com altitude mais elevada, onde a temperatura noturna é menor quando comparada com a do presente estudo, que o revestimento da ureia e o inibidor da urease foram eficientes na redução da volatilização do $\mathrm{N}$ (em torno de 50\%) da ureia aplicada em cobertura, o que refletiu em maiores produtividades de grãos. Silva et al. (2012) não encontraram diferenças significativas na produtividade de milho, quando compararam fontes de ureia revestida e convencional, aplicadas em cobertura, porém constataram acréscimo de produtividade em função do aumento da dose de $\mathrm{N}$. Possivelmente, em seu experimento, não houve redução da volatilização da amônia, pois se a planta de milho responde ao aumento de doses de $\mathrm{N}$, provavelmente responderia positivamente e forma mais expressiva à adubação em cobertura

Cultura Agronômica, Ilha Solteira, v.25, n.4, p.361-372, 2016 
com ureia protegida, em função dos benefícios do recobrimento retardando a atividade da enzima urease.

A interação foi significativa entre fontes de $\mathrm{N}$ e modos de aplicação para produtividade de matéria seca (Tabela 5), onde na aplicação em superfície no solo, o polímero orgânico C1 foi mais eficiente comparativamente ao polímero $\mathrm{C} 2$, não diferindo da ureia. $\mathrm{Na}$ aplicação incorporada, as fontes propiciaram produtividade de matéria seca semelhante. Tal resultado é um indicativo que a ureia aplicada na superfície do solo teve baixa eficiência de aproveitamento de $\mathrm{N}$ pelo milho, em decorrência de perdas por volatilização de amônia, e que ocorreram menores perdas de $\mathrm{N}$ por volatilização no polímero orgânico $\mathrm{C} 1$ em relação às demais fontes de $\mathrm{N}$.

Tabela 5. Desdobramento da interação fonte de $\mathrm{N}$ e modo de aplicação, da análise de variância referente à matéria seca de planta de milho (g por planta). Ilha Solteira - SP, 2012.

\begin{tabular}{cccc}
\hline Tratamentos & \multicolumn{4}{c}{ Fontes de N } \\
\hline Modo de aplicação & $\mathrm{C} 1^{*}$ & $\mathrm{C} 2$ & Ureia \\
\hline Incorporado & $41,69 \mathrm{aA}$ & $40,03 \mathrm{aA}$ & $41,67 \mathrm{aA}$ \\
Em superfície & $43,41 \mathrm{aA}$ & $38,14 \mathrm{aB}$ & $39,85 \mathrm{aAB}$ \\
\hline \multirow{2}{*}{ D.M.S. (5\%) } & Fontes de N & & 4,07 \\
& Doses de N & & 4,91 \\
\hline
\end{tabular}

Médias seguidas de mesma letra, minúsculas nas colunas e maiúsculas nas linhas, não diferem estatisticamente entre si pelo teste de Tukey a $5 \%$ de probabilidade.

${ }^{*} \mathrm{C} 1$ = Polímero orgânico com 30\% de ureia, perfazendo 6,86\% de N; C2 = Polímero orgânico com $70 \%$ de ureia, perfazendo $19,35 \%$ de $\mathrm{N}$; Ureia $=45 \%$ de $\mathrm{N}$.

Segundo Rodrigues et al. (2014), fertilizantes de liberação lenta ou controlada dependem de água e da temperatura do solo (ótima igual a $21^{\circ} \mathrm{C}$ ), para a adequada liberação dos nutrientes às plantas. Sendo assim, vale destacar que este experimento foi conduzido em casa de vegetação sem controle de temperatura, ou seja, as temperaturas foram tão elevadas dentro como fora da casa de vegetação. Portanto, isto demonstra que o polímero C1 tem grande potencial para condições de clima tropical.

A eficácia dos fertilizantes revestidos depende da solubilidade do polímero que reveste o grânulo e a hidrólise, o que regulará o processo de fornecimento dos nutrientes. Essas taxas de liberação e a dissolução de fertilizantes solúveis em água dependem dos materiais de revestimento (RODRIGUES et al., 2013). Ainda, de acordo com esses autores, a liberação do nutriente irá depender da temperatura e da umidade do solo. Além do mais, a espessura e a natureza química da resina de recobrimento, as quantidades de microfissuras em sua superfície e o tamanho do grânulo do fertilizante, determinam a taxa de liberação de nutrientes ao longo do tempo (RODRIGUES et al., 2014). Sendo assim, ainda há necessidade de novas pesquisas para o desenvolvimento de novos polímeros para o revestimento da ureia que possam resistir às altas temperaturas, comuns nesta região do Cerrado de baixa altitude. Destaca-se que os resultados com polímeros podem variar conforme a época de aplicação da adubação nitrogenada de cobertura e as condições climáticas no período desta aplicação, e que, não apresentam efeito residual para culturas sucessoras, superiores à ureia.

Cultura Agronômica, Ilha Solteira, v.25, n.4, p.361-372, 2016 
Tendo em vista que este polímero ainda está em fase de estudos, o resultado obtido foi satisfatório quando utilizado em casa de vegetação. Brevemente, serão realizadas mais pesquisas de campo, com o intuito de obtenção de patente deste fertilizante, uma vez que em muitos experimentos realizados com polímeros nas regiões de Cerrado, os resultados obtidos não são satisfatórios, pois são importadas tecnologias em fertilizantes de países de clima temperado.

\section{CONCLUSÕES}

1. A dose de $100 \mathrm{mg} \mathrm{dm}^{-3}$ de $\mathrm{N}$ proporciona maior teor de $\mathrm{N}$ na planta de milho, quando se utiliza o polímero orgânico $\mathrm{C} 1$ e a ureia.

2. O modo de aplicação não interfere nos teores de N, P e K na planta, contudo, o ICF3 é superior com incorporação das fontes de $\mathrm{N}$.

3. O polímero orgânico C1 foi mais eficiente quando aplicado em superfície no solo, propiciando maior matéria seca de planta de milho.

4. A utilização do polímero orgânico $\mathrm{C} 1$ mostrou-se promissor no fornecimento de $\mathrm{N}$ à planta de milho, pois proporciona maior matéria seca de planta na dose de $50 \mathrm{mg} \mathrm{dm}^{-3}$ de N que a ureia e o polímero $\mathrm{C} 2$.

\section{REFERÊNCIAS BIBLIOGRÁFICAS}

CABEZAS, W. A. R. L.; TRIVELIN, P. C. O.; KONDÖRFER, G. H.; PEREIRA, S. Balanço da adubação nitrogenada sólida e fluida de cobertura na cultura de milho, em sistema plantio direto no Triângulo Mineiro (MG). Revista Brasileira de Ciência do Solo, Viçosa, v. 24, n. 2, p.363-376, 2000.

CANTARElla, H.; RAIJ, B. V.; CAMARGO, C. E. O. Cereais. In: RAIJ, B. V.; CANTARELlA, H.; QUAGGIO, J. A.; FURLANI, A. M. C. (Eds.) Recomendações de calagem e adubação para o Estado de São Paulo. Campinas: IAC, 1997. p. 45-71. (Boletim técnico, 100).

CIVARDI, E. A.; SILVEIRA NETO, A. N. D.; RAGAGNIN, V. A.; GODOY, E. R.; BROD, E. Ureia de liberação lenta aplicada superficialmente e ureia comum incorporada ao solo no rendimento do milho. Pesquisa Agropecuária Tropical, Goiânia, v. 41, n. 1, p.52-59, 2011. COMPANHIA NACIONAL DE ABASTECIMENTO - CONAB. Avaliação da safra agrícola 2015/2016: primeiro levantamento - outubro/2015. Brasília: CONAB, 2015. Disponível

em: http://www.conab.gov.br/OlalaCMS/uploads/arquivos/15_10_09_17_45_57_boletim_graos _outubro_2015_novo.pdf . Acesso em: 12 out. 2015. 
COSTA, N. R.; ANDREOTTI, M.; GAMEIRO, R. D. A.; PARIZ, C. M.; BUZETTI, S.; LOPES, K. S. M. Adubação nitrogenada no consórcio de milho com duas espécies de braquiária em sistema plantio direto. Pesquisa Agropecuária Brasileira, Brasília, v. 47, n. 8, p.1038-1047, 2012.

CRUZ, S. C. S.; PEREIRA, F. D. S.; SANTOS, J. R.; ALBUQUERQUE, A. D.; PEREIRA, R. G. Adubação nitrogenada para o milho cultivado em sistema plantio direto, no Estado de Alagoas. Revista Brasileira de Engenharia Agrícola e Ambiental, Campina Grande, v. 12, n. 1, p.62-68, 2008.

EMPRESA BRASILEIRA DE PESQUISA AGROPECUÁRIA - EMBRAPA. Sistema brasileiro de classificação de solos. 3. ed. Brasília: Embrapa, 2013. 353 p.

FERREIRA, D. F. Sisvar: a computer statistical analysis system. Ciência e Agrotecnologia, Lavras, v. 35, n. 6, p.1039-1042, 2011.

KAPPES, C.; ARF, O.; ANDRADE, J. A. C. Produtividade do milho em condições de diferentes manejos do solo e de doses de nitrogênio. Revista Brasileira de Ciência do Solo, Viçosa, v. 37, n. 5, p.1310-1321, 2013.

MALAVOLTA, E. Elementos de nutrição de plantas. Piracicaba: Editora Agronômica Ceres, 1980. $251 \mathrm{p}$.

MALAVOLTA, E.; VITTI, G. C.; OLIVEIRA, S. A. Avaliação do estado nutricional das plantas: princípios e aplicações. 2. ed. Piracicaba: POTAFOS, 1997. 319 p.

MAR, G. D; MARCHETTI, M. E.; SOUZA, L. C. F.; GONÇALVES, M. C.; NOVELINO, J. O. Produção do milho safrinha em função de doses e épocas de aplicação de nitrogênio. Bragantia, Campinas, v. 62, n. 2, p.267-274, 2003.

PEREIRA, H. S.; LEÃO, A. F.; VERGINASSI, A.; CARNEIRO, M. A. C. Ammonia volatilization of urea in the out-of-season corn. Revista Brasileira de Ciência do Solo, Viçosa, v. 33, n. 6, p.1685-1694, 2009.

PÖTTKER, D.; WIETHÖLTER, S. Épocas e métodos de aplicação de nitrogênio em milho cultivado no sistema plantio direto. Ciência Rural, Santa Maria, v. 34, n. 4, p.1015-1020, 2004.

RAIJ, B. V.; ANDRADE, J. C.; CANTARELlA, H.; QUAGGIO, J. A. Análise química para avaliação da fertilidade de solos tropicais. Campinas: IAC, 2001. 285 p.

ROBERTSON, G. P.; GROFFMAN, P. Nitrogen transformations. In: PAUL, E. A. Soil Microbiology, Biochemistry and Ecology. New York: Springer, 2007. p. 341-364.

RODRIGUES, M. A. C.; BUZETTI, S.; TEIXEIRA FILHO, M. C. M.; GARCIA, C. M. P.; ANDREOTTI, M. Adubação com $\mathrm{KCl}$ revestido na cultura do milho no Cerrado. Revista Brasileira de Engenharia Agrícola e Ambiental, Campina Grande, v. 18, n. 2, p.127-133, 2014.

Cultura Agronômica, Ilha Solteira, v.25, n.4, p.361-372, 2016 
RODRIGUES, M. A. C.; BUZETTI, S.; MAESTRELO, P. R.; LINO, A. C. M.; TEIXEIRA FILHO, M. C. M.; ANDREOTTI, M.; GARCIA, C. M. P. Cloreto de potássio revestido em efeito residual no feijoeiro de inverno irrigado na região de Cerrado. Semina: Ciências Agrárias, Londrina, v. 34, n. 3, p.1011-1022, 2013.

SILVA, A. A.; SILVA, T. S.; DE VASCONCELOS, A. C. P.; LANA, R. M. Q. Aplicação de deferentes fontes de ureia de liberação gradual na cultura do milho. Bioscience Journal, Uberlândia, v. 28, Suppl. 1, p.104-111, 2012.

SILVA, E. C.; BUZETTI, S.; GUIMARÃES, G. L.; LAZARINI, E.; SÁ, M. E. Doses e épocas de aplicação de nitrogênio na cultura do milho em plantio direto sobre Latossolo Vermelho. Revista Brasileira de Ciência do Solo, Viçosa, v. 29, n. 3, p.353-362, 2005.

SOUZA, J. A.; BUZETTI, S; TEIXEIRA FILHO, M. C. M.; ANDREOTTI, M.; SÁ, M. E.; ARF, O. Adubação nitrogenada na cultura do milho safrinha irrigado em plantio direto. Bragantia, Campinas, v. 70, n. 2, p.447-454, 2011.

SORATTO, R. P.; PEREIRA, M.; COSTA, T. A. M.; LAMPERT, V. N. Fontes alternativas e doses de nitrogênio no milho safrinha em sucessão à soja. Revista Ciência Agronômica, Fortaleza, v. 41, n. 4, p.511-518, 2010.

VALDERRAMA, M.; BUZETTI, S.; BENETT, C. G. S.; ANDREOTTI, M.; TEIXEIRA FILHO, M. C. M. Fontes e doses de NPK em milho irrigado sob plantio direto. Pesquisa Agropecuária Tropical, Goiânia, v. 41, n. 2, p.254-263, 2011. 